\title{
4-Hydroxyl-N'-[(3-Hydroxy-4-Methoxyphenyl) Methylidene] Benzohydrazide] as Corrosion Inhibitor for Carbon Steel in Dilute $\mathrm{H}_{2} \mathrm{SO}_{4}$
}

\author{
Nikshith G. Poojary • Preethi Kumari • Suma A. Rao
}

Submitted: 14 January 2021/in revised form: 16 April 2021 / Accepted: 3 May 2021 / Published online: 2 June 2021

(C) The Author(s) 2021

\begin{abstract}
The effect of an aromatic hydrazide derivative 4-hydroxyl- $\mathrm{N}^{\prime}$-[(3-hydroxy-4-methoxyphenyl) methylidene] benzohydrazide] (HMBH) as inhibitor for the corrosion of carbon steel in $0.5 \mathrm{M} \mathrm{H}_{2} \mathrm{SO}_{4}$ solution was investigated in the temperature range of $303 \mathrm{~K}$ to $323 \mathrm{~K}$ using potentiodynamic polarization (PDP) and electrochemical impedance spectroscopy (EIS). The concentration of HMBH used was in the range of 0.1 to $1 \mathrm{mM}$. Inhibition efficiency (\% IE) increased with increase in concentration of $\mathrm{HMBH}$ and decreased with increase in temperature. Maximum \% IE obtained was around 71 with $1 \times 10^{-3} \mathrm{M}$ $\mathrm{HMBH}$ in $0.5 \mathrm{M} \mathrm{H}_{2} \mathrm{SO}_{4}$ at $303 \mathrm{~K}$. The Tafel polarization results indicate that $\mathrm{HMBH}$ acted as a mixed type of inhibitor. The results of evaluation of thermodynamic and activation parameters suggest the mixed adsorption of HMBH took place by physisorption, and it obeyed Freundlich's isotherm. Scanning electron microscope (SEM) and atomic force spectroscopy (AFM) images were also recorded to supplement the results of electrochemical studies, and mechanism for corrosion inhibition was suggested.
\end{abstract}

Keywords Carbon steel - Aromatic hydrazide . Acid corrosion - Electrochemical methods . Adsorption studies · Surface morphology

N. G. Poojary · P. Kumari · S. A. Rao (ه)

Department of Chemistry, Manipal Institute of Technology, Manipal Academy of Higher Education, Manipal 576104, India e-mail: suma.rao@manipal.edu

\section{Introduction}

Carbon steel (CS) being one of the important engineering materials in existence has wide applications in industrial fields due to its exceptional mechanical properties and low cost. It is widely used in large tonnages as construction materials in many industries, marine and chemical process equipment $[1,2]$. Dilute solutions of mineral acids like $\mathrm{HCl}$ and $\mathrm{H}_{2} \mathrm{SO}_{4}$ are commonly used in many industries for descaling, pickling, petrochemical processes and oil-well acidification. However, the corrosion rate of CS particularly in acid medium can be combated using inhibitors $[3,4]$. Critical use of organic compounds containing hetero atoms such as $\mathrm{N}, \mathrm{S}$ or $\mathrm{O}$ has been reviewed and found to function as better adsorption inhibitors owing to their free (donor) electron pair and polar nature of the molecules $[5,6]$.

The ability of the hydrazide derivatives [7-9], and thiosemicarbazide derivatives [10-13], to inhibit corrosion of CS in acid medium is well established. Thus, as a part of the research work with inhibitors for the corrosion control of steel we report herein the results of the synthesis of a hydrazide derivative, namely 4-hydroxyl- $\mathrm{N}^{\prime}$-[(3-hydroxy4-methoxyphenyl) methylidene] benzohydrazide](HMBH) and its inhibition action on CS in $0.5 \mathrm{M} \mathrm{H}_{2} \mathrm{SO}_{4}$ medium with four levels of concentration of the inhibitor at three different temperatures (303 to $323 \mathrm{~K}$ ) along with the images of SEM and AFM with and without the inhibitor. 


\section{Experimental Details}

\section{Material}

The corrosion tests were conducted on the plain CS specimen having the composition given in Table 1.

\section{Test Specimen Preparation}

Cylindrical test coupons of CS material with external cross-sectional surface area of $1 \mathrm{~cm}^{2}$ were prepared and then mounted with cold setting resin. The polishing was done using emery paper of different grades (200-1200) and finally disc polished by means of levigated alumina. The freshly polished specimen was then washed with distilled water and dried.

\section{Preparation of Medium}

Stock solution of higher concentration of approximately $1 \mathrm{M}$ solution of $\mathrm{H}_{2} \mathrm{SO}_{4}$ was prepared from $\mathrm{AR} \mathrm{H}_{2} \mathrm{SO}_{4}$ and standardized by volumetric method. From this, the required concentrations of $0.5 \mathrm{M} \mathrm{H}_{2} \mathrm{SO}_{4}$ were prepared by appropriate dilution as and when required.

\section{Synthesis of HMBH}

The reactants 3-hydroxy-4-methoxy benzaldehyde and 4hydroxy benzo hydrazide were taken in $1: 1$ ratio in a round-bottom flask to which the required amount of ethanol and two drops of glacial acetic acid were added and refluxed for 3-4 h. Filtered residue was collected and dried. The synthesis of HMBH is shown in Fig. 1.

\section{Electrochemical Techniques}

Electrochemical impedance spectroscopy $(E I S)$ and potentiodynamic polarization $(P D P)$ studies were performed using an electrochemical workstation $(\mathrm{CH}$ Instrument USA Model 604D series with beta software). The measurements were taken using a saturated calomel electrode as the reference electrode and platinum as the counter electrode. The CS specimen was used as the working electrode. The finely polished specimen of CS was exposed to $0.5 \mathrm{M}$ sulfuric acid with $0,0.1,0.25$, 0.5 and $1.0 \mathrm{mM} \mathrm{HMBH}$ at three different temperatures (303, 313 and $323 \mathrm{~K}$ ) and allowed to establish a steady-

Table 1 Composition of the CS.

\begin{tabular}{ccccccc}
\hline Element & $\mathrm{C}$ & $\mathrm{Si}$ & $\mathrm{Mn}$ & $\mathrm{P}$ & $\mathrm{S}$ & $\mathrm{Fe}$ \\
\hline wt.\%) & 0.49 & 0.10 & 0.71 & 0.018 & 0.008 & 98.6 \\
\hline
\end{tabular}

state open-circuit potential $(O C P)$. The potentiodynamic polarization studies were then carried out in the potential range of $-250 \mathrm{mV}$ cathodically to $+250 \mathrm{mV}$ anodically at a scan rate of $0.1 \mathrm{mV} / \mathrm{s}$. Tafel plots were recorded. The corrosion rates were calculated from electrochemical data. Similarly, by applying a small amplitude of AC signal of $10 \mathrm{mV}$ to the system in the frequency range $(10 \mathrm{kHz}$ to $0.01 \mathrm{~Hz}$ ) with respect to OCP, Nyquist plots were generated.

\section{Surface Morphology Study}

The corroded surface morphology of the CS specimen dipped in $0.5 \mathrm{M} \mathrm{H}_{2} \mathrm{SO}_{4}$ solution for $2 \mathrm{~h}$ in both the absence and presence of $\mathrm{HMBH}$ was compared by recording with a SEM (JEOL JSM-6380 L) and AFM (1B342 Innova model) images.

\section{Results and Discussion}

\section{HMBH Characterization}

The characterization of HMBH was conducted using Shimadzu FTIR 8400S spectrophotometer. Figure 2 shows the IR spectrum of the HMBH molecule.

Characterization of HMBH: $3451 \mathrm{~cm}^{-1}(\mathrm{OH}), 3221 \mathrm{~cm}^{-}$ ${ }^{1}(\mathrm{NH}), 3093 \mathrm{~cm}^{-1}$ and $3052 \mathrm{~cm}^{-1}$ (Ar.CH), $2940 \mathrm{~cm}^{-1}$ and $2964 \mathrm{~cm}^{-1}\left(\mathrm{CH}_{3}\right), 1606 \mathrm{~cm}^{-1}(\mathrm{C}=\mathrm{O}), 1585 \mathrm{~cm}^{-1}(\mathrm{C}=\mathrm{N})$.

\section{Potentiodynamic Polarization (PDP) Measurements}

The PDP curves for the corrosion of CS in $0.5 \mathrm{M} \mathrm{H}_{2} \mathrm{SO}_{4}$ at $303 \mathrm{~K}$ in the absence and presence of $\mathrm{HMBH}$ are shown in Fig. 3. Plots obtained at other temperatures were similar. The full data are tabulated in Table 2.

From the potentiodynamic polarization plots, important electrochemical parameters like corrosion current density $\left(i_{\text {corr }}\right)$, corrosion potential $\left(E_{\text {corr }}\right)$, cathodic and anodic Tafel slopes, $\left(\beta_{a}\right.$ and $\left.\beta_{c}\right)$ can be obtained, and hence, corrosion rate was calculated using the following equation:

$C R=\frac{3270 \times M \times i_{\text {corr }}}{\rho \times Z}$

$i_{\text {corr }}=$ corrosion current density in $\mathrm{A} \mathrm{cm}^{-2}, 3270=\mathrm{a}$ constant that defines the conversion unit, $\rho=$ density of the corroding material $\left(7.725 \mathrm{~g} \mathrm{~cm}^{-3}\right), Z=$ number of electrons transferred per metal atom $\left(Z=2\right.$ for $\left.\mathrm{Fe} \rightarrow \mathrm{Fe}^{2+}\right), \mathrm{M}=$ atomic mass of the metal (55.85) [14].

Inhibition efficiency $(\% I E)$ of the inhibitor was calculated using the equation 
Fig. 1 Synthesis of 4-hydroxyl$\mathrm{N}^{\prime}$-[(3-hydroxy-4methoxyphenyl)methylidene] benzohydrazide] (HMBH)

Fig. 2 IR spectrum for $\mathrm{HMBH}$

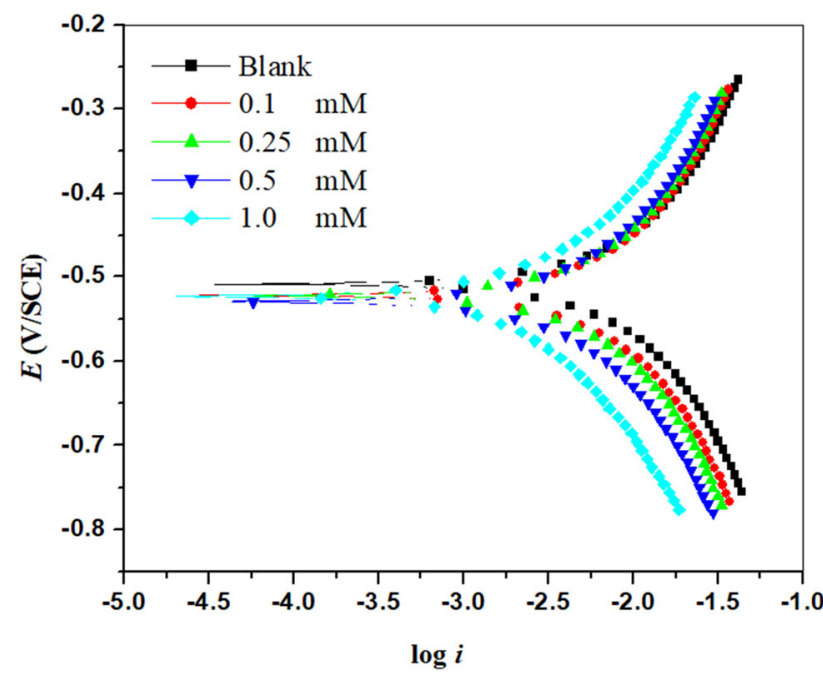

Fig. 3 Polarization curves (E vs $\log$ i) for $C S$ corrosion in $0.5 \mathrm{M}$ $\mathrm{H}_{2} \mathrm{SO}_{4}$ solution at $303 \mathrm{~K}$ with different amounts of $\mathrm{HMBH}$

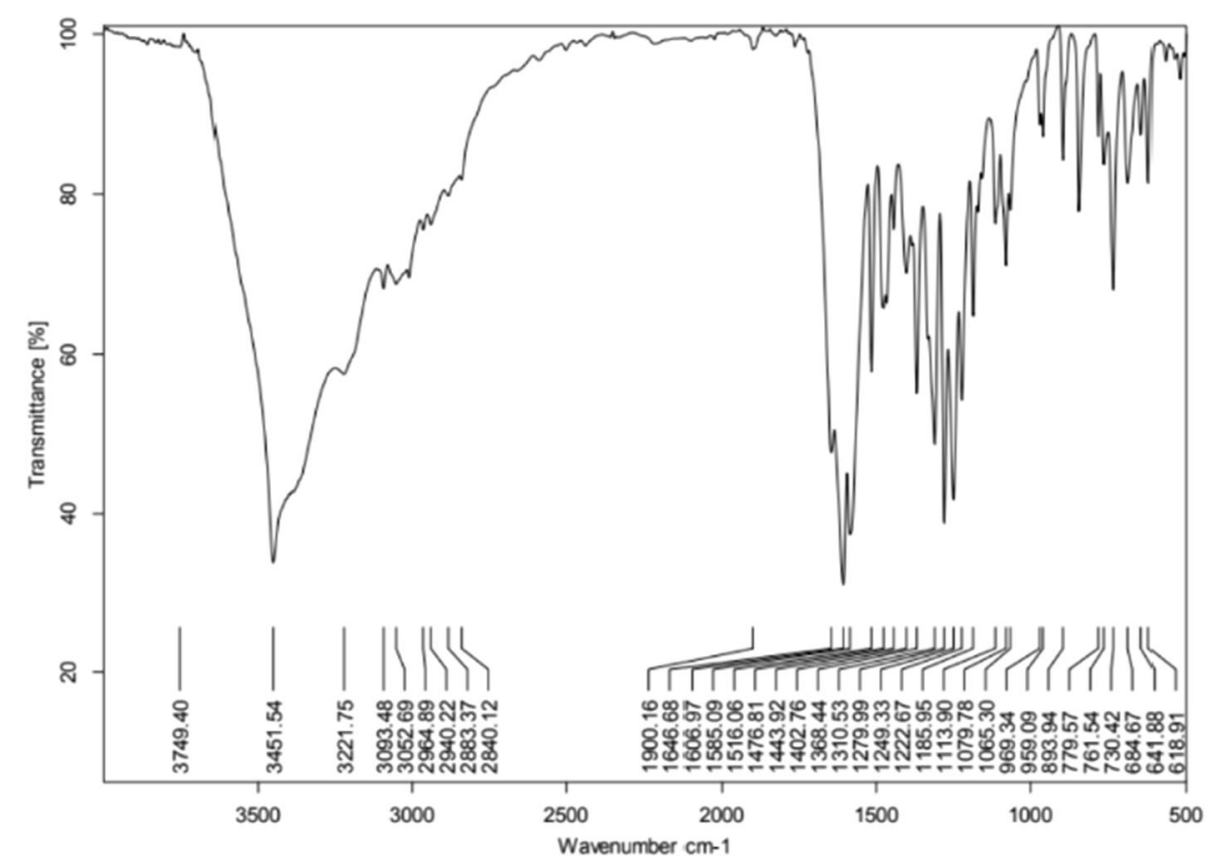

$I E(\%)=\frac{i_{\text {corr }}-i_{\text {corr }(\mathrm{inh})}}{i_{\text {corr }}} \times 100$

where $i_{\text {corr }}$ represents the corrosion current density in uninhibited solution and $i_{\text {corr (inh) }}$ is in the inhibited condition [15].

The fraction of surface covered $(\theta)$ is given by

$\theta=\frac{I E(\%)}{100}$

It is evident that as the concentration of $\mathrm{HMBH}$ increases, there is a reduction in $i_{\text {corr }}$ and hence decrease in corrosion rate. Table 2 shows the \% IE increases with the increase in concentration of added $\mathrm{HMBH}$. This may be due to the adsorbed inhibitor covering the active metal surface by film formation. The maximum inhibition efficiency obtained is about $71 \%$ in $0.5 \mathrm{M} \mathrm{H}_{2} \mathrm{SO}_{4}$ at 303 $\mathrm{K}$. From the Tafel plots it is observed that there is no remarkable variation in the slope values (both anodic and cathodic) after the addition of inhibitor. This suggests that added inhibitor $\mathrm{HMBH}$ brings down the corrosion rate without altering the mechanism of corrosion. It simply 
blocks the anodic and cathodic regions in the form of the physical barrier and thus controls reactions of both dissolutions of metal and hydrogen liberation [16].

Shift in the corrosion potential $\left(E_{\text {corr }}\right)$ value in the presence of HMBH is very little. If the shift in the corrosion potential exceeds $\pm 85 \mathrm{mV}$ with respect to corrosion potential of the uninhibited solution, then the inhibitor may be considered as either anodic or cathodic type [17]. In the present case, the shift in the $E_{\text {corr }}$ values is well within the limiting range and hence $\mathrm{HMBH}$ can be considered as mixed-type inhibitor.

Table 2 Results of potentiodynamic polarization measurements for the corrosion of $\mathrm{CS}$ in $0.5 \mathrm{M} \mathrm{H}_{2} \mathrm{SO}_{4}$ in the absence and presence of $\mathrm{HMBH}$ at different temperatures

\begin{tabular}{|c|c|c|c|c|c|c|c|}
\hline $\begin{array}{l}\text { Temp } \\
(\mathrm{K})\end{array}$ & $\begin{array}{c}{[\mathrm{HMBH}]} \\
(\mathrm{mM})\end{array}$ & $\begin{array}{c}E_{\text {corr }} \\
\text { (V/ } \\
\text { SCE) }\end{array}$ & $\begin{array}{c}-\beta c \\
\left(\operatorname{Vdec}^{-1}\right)\end{array}$ & $\begin{array}{c}B a \\
\left(\operatorname{Vdec}^{-1}\right)\end{array}$ & $\begin{array}{c}i_{\text {corr }} \\
(\mathrm{mA} \\
\left.\mathrm{cm}^{-2}\right)\end{array}$ & $\begin{array}{c}C R \\
\text { (mpy) }\end{array}$ & $\begin{array}{l}\% \\
I E\end{array}$ \\
\hline \multirow[t]{5}{*}{303} & 0.00 & -0.509 & 4.969 & 4.918 & 7.158 & 3323 & $\ldots$ \\
\hline & 0.10 & -0.522 & 5.026 & 5.015 & 6.027 & 2798 & 15.8 \\
\hline & 0.25 & -0.522 & 5.171 & 5.169 & 5.120 & 2377 & 28.5 \\
\hline & 0.50 & -0.529 & 5.245 & 5.490 & 3.947 & 1832 & 45.0 \\
\hline & 1.00 & -0.523 & 5.414 & 6.089 & 2.069 & 960 & 71.1 \\
\hline \multirow[t]{5}{*}{313} & 0.00 & -0.511 & 5.084 & 5.142 & 8.045 & 3735 & $\ldots$ \\
\hline & 0.10 & -0.519 & 5.216 & 4.942 & 6.820 & 3166 & 15.2 \\
\hline & 0.25 & -0.527 & 5.446 & 4.775 & 6.346 & 2946 & 21.1 \\
\hline & 0.50 & -0.521 & 5.127 & 5.028 & 5.065 & 2352 & 37.0 \\
\hline & 1.00 & -0.529 & 5.172 & 5.287 & 3.792 & 1761 & 52.9 \\
\hline \multirow[t]{5}{*}{323} & 0.00 & -0.507 & 4.999 & 5.097 & 11.60 & 5383 & $\ldots$ \\
\hline & 0.10 & -0.515 & 4.288 & 4.932 & 10.11 & 4694 & 12.8 \\
\hline & 0.25 & -0.519 & 5.093 & 5.012 & 9.86 & 3002 & 19.6 \\
\hline & 0.50 & -0.514 & 4.998 & 4.959 & 8.67 & 4029 & 25.2 \\
\hline & 1.00 & -0.522 & 5.082 & 4.855 & 8.03 & 3732 & 30.7 \\
\hline
\end{tabular}

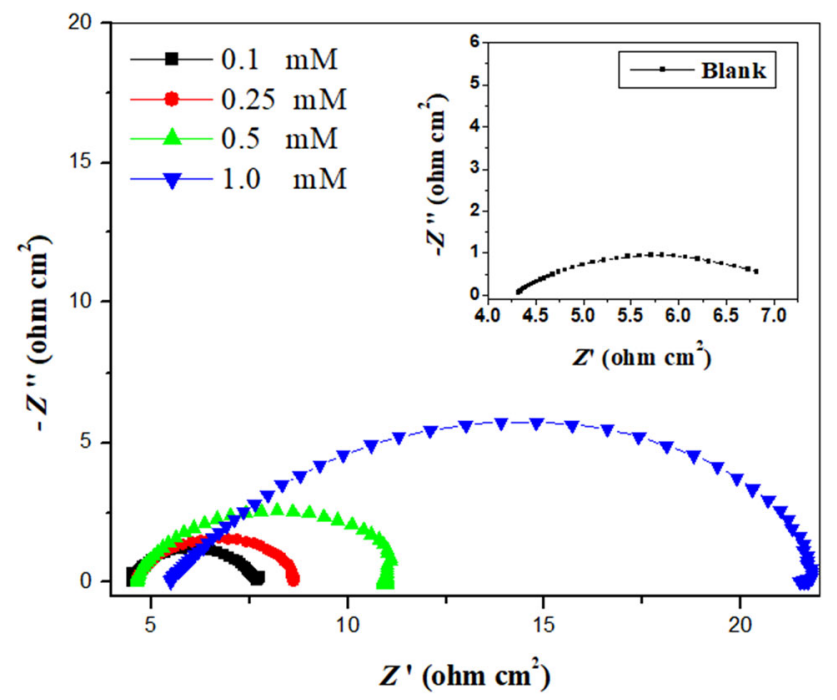

Fig. 4 Nyquist plots for the $\mathrm{CS}$ specimen in $0.5 \mathrm{M} \mathrm{H}_{2} \mathrm{SO}_{4}$ at $303 \mathrm{~K}$ containing different concentrations of inhibitor.
Impedance Spectroscopic Studies

In electrochemical impedance spectroscopy studies, the real (resistance) and imaginary (capacitance) components were recorded. Impedance data were evaluated using Nyquist plots. Nyquist plots obtained for the CS specimen in $0.5 \mathrm{M} \mathrm{H}_{2} \mathrm{SO}_{4}$ at $303 \mathrm{~K}$ containing different concentrations of HMBH are shown in Fig. 4. The Nyquist plots are characterized by a capacitive loop in the high-frequency $(H F)$ region which could be assigned to the charge transfer of the corrosion process. Further, the diameter of the capacitive loop increased with increase in the concentration of HMBH. From Fig. 4 it is observed that there is depression in the semicircles. This could be due to the

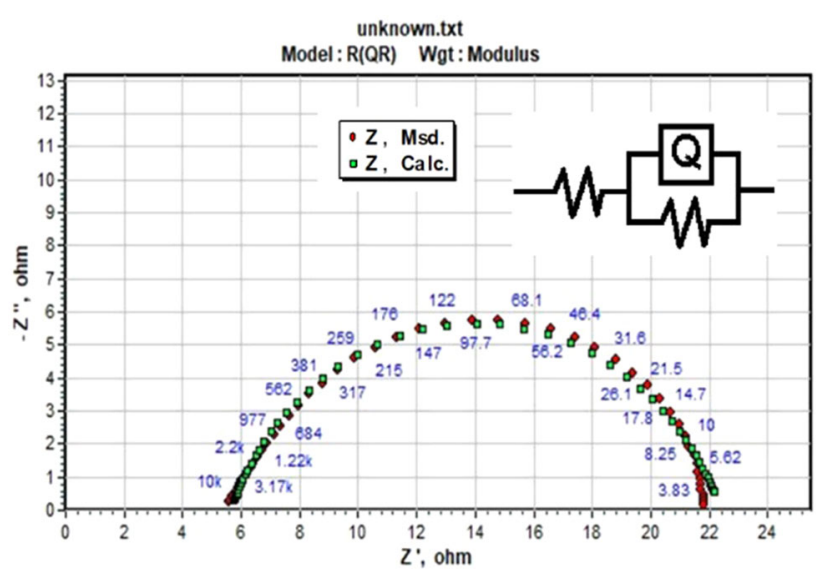

Fig. 5 Equivalent circuit used to fit experimental EIS data for the corrosion of $\mathrm{CS}$ in $0.5 \mathrm{M} \mathrm{H}_{2} \mathrm{SO}_{4}$.

Table 3 EIS parameters for corrosion inhibition behavior of HMBH on $\mathrm{CS}$ in $0.5 \mathrm{M} \mathrm{H}_{2} \mathrm{SO}_{4}$ at various temperatures.

\begin{tabular}{lcccl}
\hline Temp (K) & {$[\mathrm{HMBH}](\mathrm{mM})$} & $R p\left(\Omega \mathrm{cm}^{2}\right)$ & $C d l\left(\mu \mathrm{F} \mathrm{cm}{ }^{-2}\right)$ & $\% I E$ \\
\hline 303 & 0.0 & 2.6 & 65138 & $\ldots$ \\
& 0.10 & 3.0 & 44868 & 16.20 \\
& 0.25 & 3.7 & 26681 & 29.25 \\
& 0.50 & 5.3 & 11175 & 48.00 \\
313 & 1.00 & 9.0 & 3111 & 71.10 \\
& 0.00 & 2.8 & 120283 & $\ldots$ \\
& 0.10 & 3.3 & 46893 & 15.50 \\
& 0.25 & 3.7 & 27170 & 24.30 \\
323 & 0.50 & 4.2 & 20866 & 33.40 \\
& 1.00 & 5.4 & 7477 & 48.20 \\
& 0.00 & 1.2 & 342885 & $\ldots$ \\
& 0.10 & 1.4 & 249429 & 14.20 \\
& 0.25 & 1.5 & 219696 & 20.00 \\
& 0.50 & 1.7 & 129394 & 29.00 \\
& 1.00 & 1.8 & 87243 & 33.00 \\
\hline
\end{tabular}


surface roughness, inhomogeneity of the solid surface and adsorption of the inhibitor on the metal surface [18, 19].

Figure 5 which represents a simple Randle's circuit is the suitable equivalent circuit used to simulate the impedance data in the presence of $\mathrm{HMBH}$. The equivalent circuit consists of the following: the solution resistance $\left(R_{\mathrm{S}}\right)$, charge transfer resistance $\left(R_{\mathrm{ct}}\right)$ and time constant phase element $(Q)$. The $Q$ is introduced in the circuit instead of a pure double-layer capacitance to account for the depressed capacitive nature of the Nyquist plots. The small variation in the capacitance from its real value was calculated using the relationship

$Z_{(\mathrm{CPE})}=Q^{-1}\left(\mathrm{I}_{\max }\right)^{-\mathrm{n}}$

where $W_{\max }=$ angular frequency, $Q=$ proportionality coefficient, $I=$ imaginary number, and $n$ is the exponent linked to the phase shift. The value of phase shift $(n)$ is

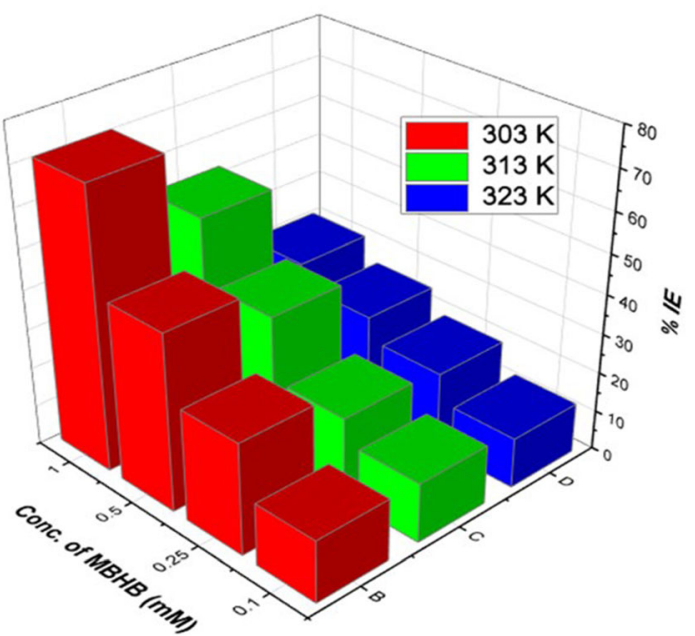

Fig. 6 Variation of \% IE with varying concentrations of $\mathrm{HMBH}$ at different temperatures

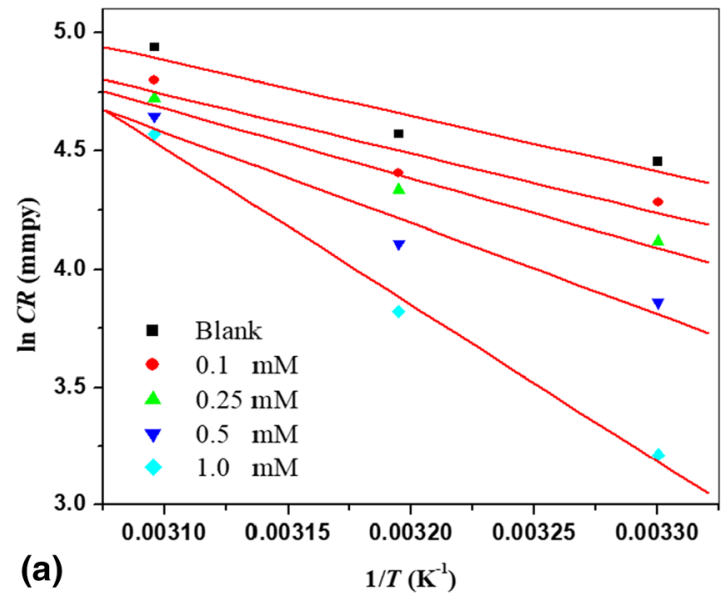

between 0 and 1 . This in turn is related to the deviation of CPE from the ideal capacitive behavior. The correction in the capacitance is given by the following equation [20]

$C_{\mathrm{dl}}=\frac{1}{2 \pi R_{\mathrm{ct}} f_{\max }}$

where $C_{\mathrm{dl}}$ is the double-layer capacitance, $R_{\mathrm{ct}}$ is the charge transfer resistance, and $f_{\max }$ is the frequency at which the imaginary part of the impedance is maximum. The charge transfer resistance $\left(R_{\mathrm{ct}}\right)$ is inversely proportional to corrosion current density $\left(i_{\text {corr }}\right)$ which is used to calculate the inhibition efficiency using the following relation.

$\% I E=\frac{R_{\mathrm{ct}(\mathrm{inh})}-R_{\mathrm{ct}}}{R_{\mathrm{ct}(\mathrm{inh})}} \times 100$

where $R_{\mathrm{ct}}$ and $R_{\mathrm{ct}(\mathrm{inh})}$ are the charge transfer resistance for the blank and in the presence of HMBH. Results obtained are tabulated in Table 3 .

It is evident from Table 3 that with the increase in HMBH concentration, the $R_{c t}$ values increased due to resistance to corrosion offered by the added inhibitor. Lowering of $C_{d l}$ values as amounts of $\mathrm{HMBH}$ increased may be attributed to lowering of dielectric constant and also increased in double-layer thickness at metal/solution

Table 4 Activation parameters for corrosion of CS in $0.5 \mathrm{M} \mathrm{H}_{2} \mathrm{SO}_{4}$ solution containing different amounts of $\mathrm{HMBH}$

\begin{tabular}{lccc}
\hline $\begin{array}{l}\text { Conc. of } \\
\mathrm{HMBH}(\mathrm{mM})\end{array}$ & $E_{\mathrm{a}}\left(\mathrm{kJmol}^{-1}\right)$ & $\Delta H^{\#}\left(\mathrm{kJmol}^{-1}\right)$ & $-\Delta S^{\#}\left(\mathrm{Jmol}^{-1} \mathrm{~K}^{-1}\right)$ \\
\hline 0.00 & 19.51 & 16.91 & 0.152 \\
0.10 & 20.85 & 18.25 & 0.149 \\
0.25 & 24.52 & 21.92 & 0.138 \\
0.50 & 31.92 & 29.32 & 0.116 \\
1.00 & 55.11 & 52.51 & 0.045 \\
\hline
\end{tabular}

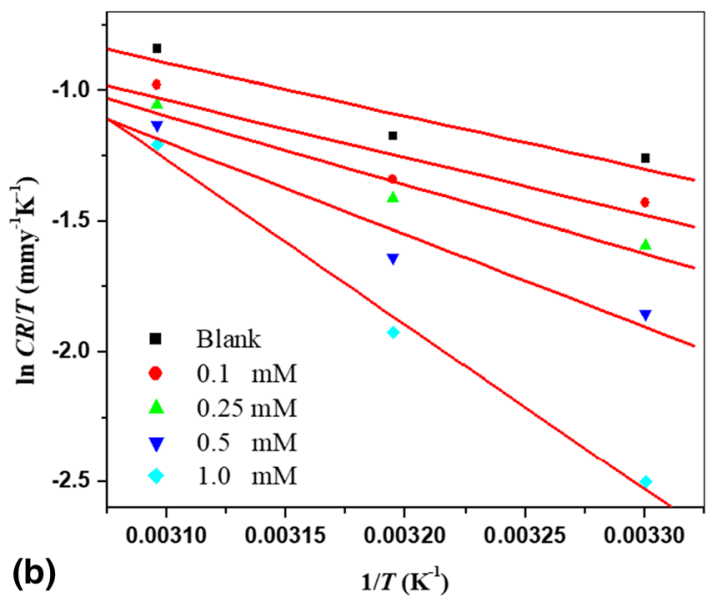

Fig. 7 Plots of (a) $\ln (\mathrm{CR})$ vs $1 / \mathrm{T}$ (b) $\ln (\mathrm{CR} / \mathrm{T})$ Vs $\mathrm{T}$ for $\mathrm{CS}$ in $0.5 \mathrm{M} \mathrm{H}_{2} \mathrm{SO}_{4}$ with different concentrations of $\mathrm{HMBH}$. 

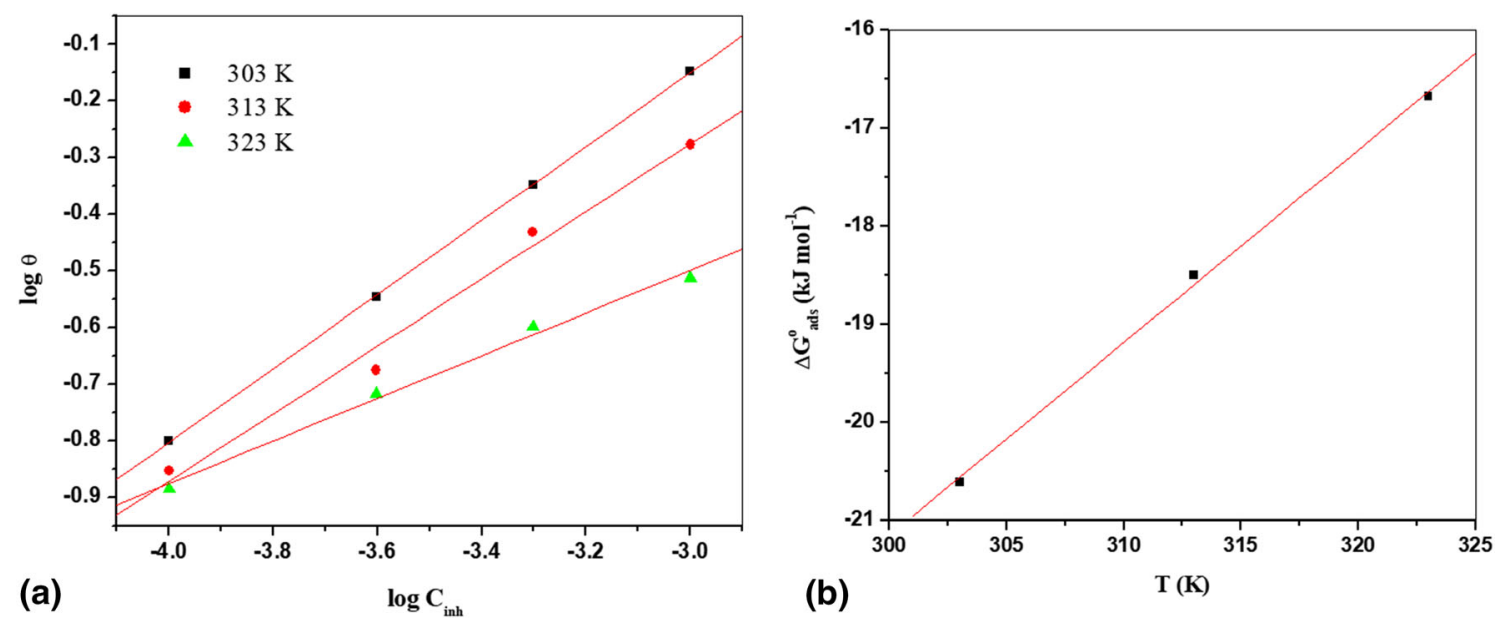

Fig. 8 (a) Freundlich adsorption isotherm for adsorption of $\mathrm{HMBH}$ on $\mathrm{CS}$ in $0.5 \mathrm{M} \mathrm{H}_{2} \mathrm{SO}_{4}$ at different temperatures. (b) Plot of $\Delta \mathrm{G}^{\circ}$ ads $\mathrm{vs}$. $\mathrm{T}$

Table 5 Thermodynamic parameters for adsorption of inhibitor on carbon steel surface in $0.5 \mathrm{M} \mathrm{H}_{2} \mathrm{SO}_{4}$.

\begin{tabular}{lccccc}
\hline Temp & $\begin{array}{c}\mathrm{K}_{\text {ads }} \\
\left(\mathrm{M}^{-1}\right)\end{array}$ & $R^{2}$ & $\begin{array}{c}\Delta \mathrm{G}^{\mathrm{o}} \text { ads } \\
\left(\mathrm{kJmol}^{-1}\right)\end{array}$ & $\begin{array}{c}\Delta \mathrm{H}^{\mathrm{o}}{ }_{\mathrm{ads}} \\
\left(\mathrm{kJmol}^{-1}\right)\end{array}$ & $\begin{array}{c}\Delta \mathrm{S}^{\mathrm{o}}{ }_{\mathrm{ads}} \\
\left(\mathrm{kJmol}^{-1} \mathrm{~K}^{-1}\right)\end{array}$ \\
\hline 303 & 64.42 & 0.999 & -20.6 & -80.1 & -0.1965 \\
313 & 22.36 & 0.993 & -18.5 & & \\
323 & 8.469 & 0.996 & -16.5 & & \\
\hline
\end{tabular}

interface [21]. The inhibition efficiency obtained from PDP and EIS techniques is in good agreement.

Evaluation of Kinetic Parameters

It can be seen from Table 2 that $\% I E$ decreases with increase in temperature in $0.5 \mathrm{M} \mathrm{H}_{2} \mathrm{SO}_{4}$. This may be due to decrease in the protective nature of the inhibitive film formed on the metal surface and desorption of the HMBH molecules at higher temperature [22]. The variation of \% $I E$ with varying concentrations of $\mathrm{HMBH}$ at different temperatures is depicted in Fig. 6.

Arrhenius equation given below was used for calculation of the activation energy $\left(E_{\mathrm{a}}\right)$ for corrosion of CS in 0.5 $\mathrm{M} \mathrm{H}_{2} \mathrm{SO}_{4}$ medium [23]

$\ln (C R)=B-\frac{E_{\mathrm{a}}}{R T}$

where $R$ is the universal gas constant, and $B$ is the Arrhenius pre-exponential constant.

Figure 7a shows the plot of $\ln (C R)$ against 1/T. Slope $\left(-E_{a} / R\right)$ is used to calculate the activation energy for the corrosion process in both the absence and presence of inhibitor and is tabulated in Table 4. The presence of the inhibitor increases the energy barrier for the corrosion reaction. Hence, the $E_{\mathrm{a}}$ values are greater in the presence of $\mathrm{HMBH}$ than without HMBH [24]. The change in enthalpy
$\left(\Delta H^{\#}\right)$ and change in entropy $\left(\Delta S^{\#}\right)$ of activation for the metal dissolution process both with and without inhibitor were determined using the transition state equation given below and are recorded in Table 4. Plot of $\ln (C R / T) \mathrm{v} / \mathrm{s} 1 / T$ (Fig. 7b) gives a straight line with slope $\left(-\Delta H^{\#} / R\right)$ and intercept $\ln (R / N h)+\left(\Delta S^{\#} / R\right)$.

$C R=\frac{R T}{N h} \exp \left(\frac{\Delta S^{\#}}{R}\right) \exp \left(\frac{-\Delta H^{\#}}{R T}\right)$

The negative values of $\Delta S^{\neq}$mean that there is less randomness in the activated complex due to association. The positive sign of the $\Delta H^{\neq}$showed the endothermic nature of steel dissolution process [25].

\section{Adsorption Considerations}

By appropriately fitting the experimental results of the present study to different adsorption isotherm models, the fraction of surface covered $(\theta)$ for various concentrations of the HMBH was determined. The best correlation was with Freundlich's adsorption isotherm which can be represented by the equation.

$\theta=\mathrm{KC}^{\mathrm{n}}$

where $C$ is the HMBH concentration and $\mathrm{K}$ is adsorption equilibrium constant whose value is obtained from the plot of $\log \theta$ vs $\log C$ (Fig. 8a).

The standard free energy of adsorption of the inhibitor $\Delta G_{\text {ads }}^{o}$ is related to adsorption/desorption constant $K$ as shown in the equation below.

$K=\frac{1}{55.5} \exp \left(\frac{-\Delta G_{\mathrm{ads}}^{\circ}}{R T}\right)$

where $K$ is the equilibrium constant, $T$ is absolute temperature, $R$ is the universal gas constant, and 55.5 is the concentration of water in solution in $\mathrm{mol} / \mathrm{dm}^{3}$ [26]. 

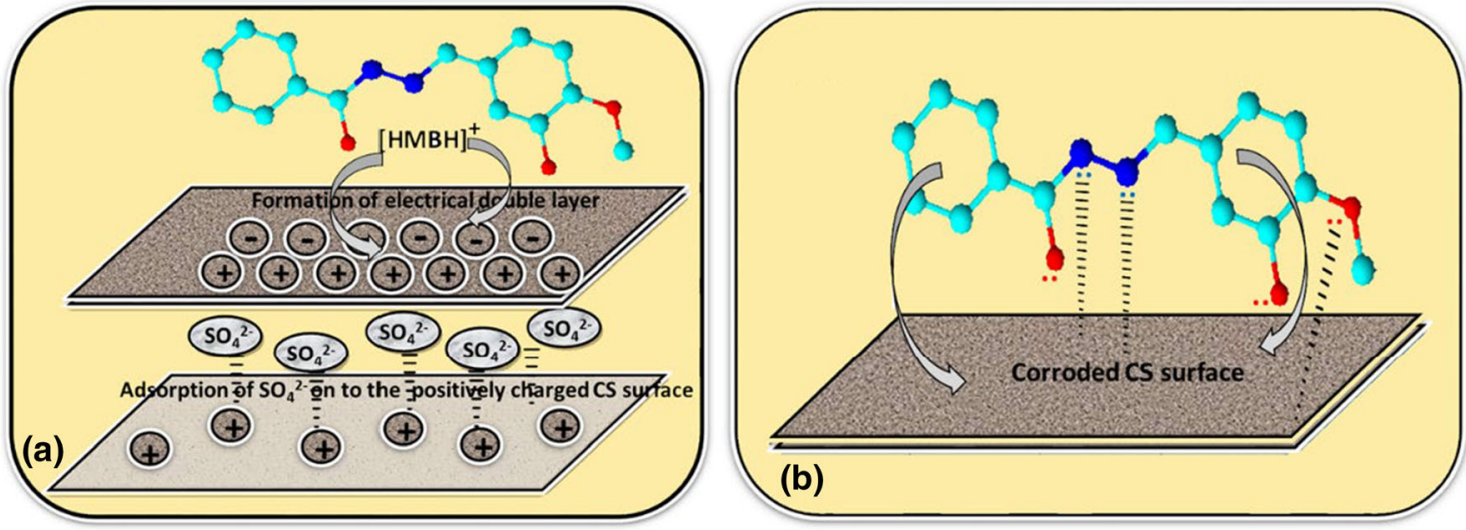

Fig. 9 Schematic representation for the corrosion inhibition through (a) electrostatic interaction and (b) electron transfer
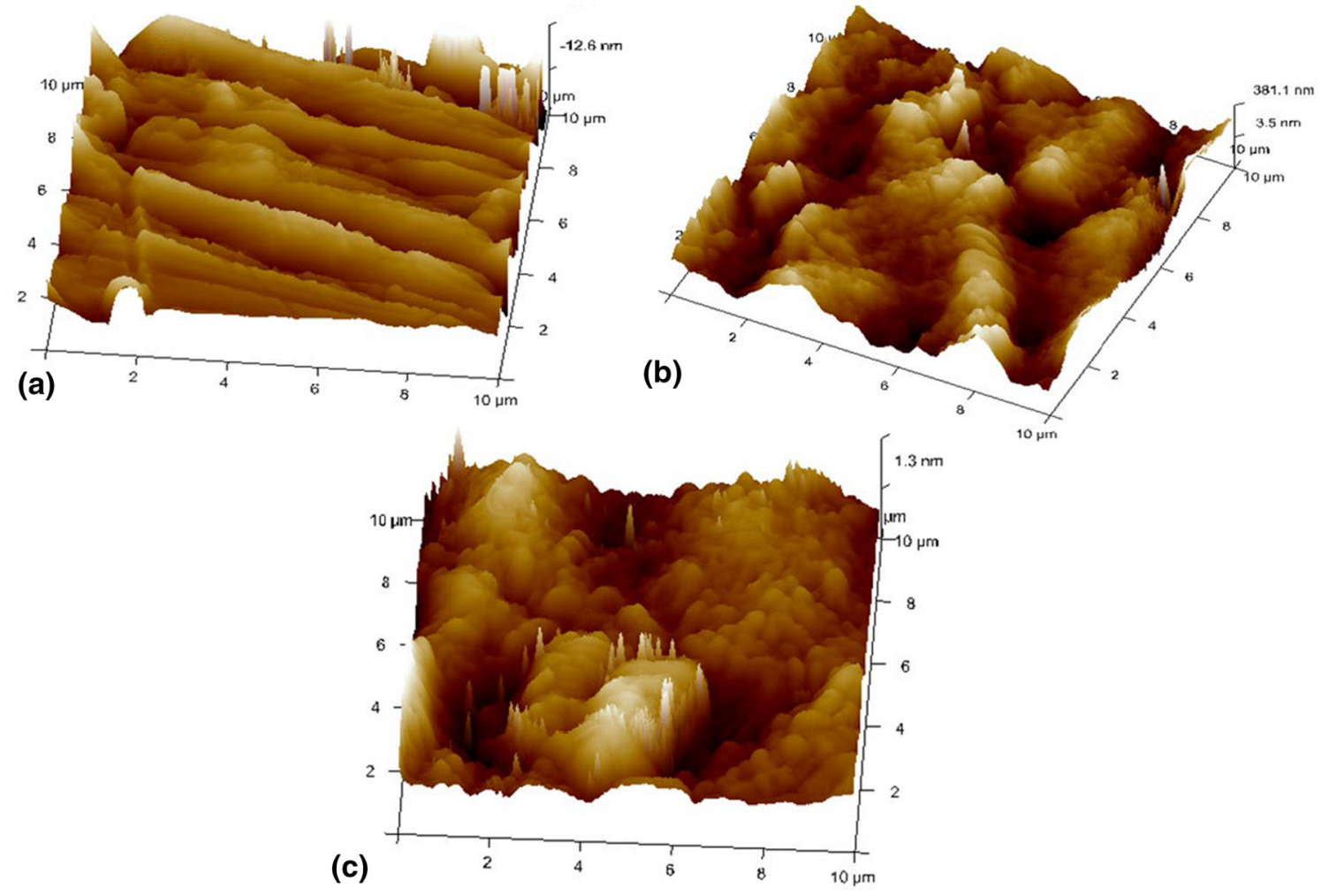

Fig. 10 Atomic force photomicrographs of CS surface. (a) Freshly polished metal, (b) immersed in $0.5 \mathrm{M} \mathrm{H}_{2} \mathrm{SO}_{4}$ and (c) immersed in $0.5 \mathrm{M}$ $\mathrm{H}_{2} \mathrm{SO}_{4}$ containing $1 \mathrm{mM}$ of $\mathrm{HMBH}$.

Table 6 Surface roughness results obtained for carbon steel in $0.5 \mathrm{M}$ $\mathrm{H}_{2} \mathrm{SO}_{4}$ in the absence and presence $\mathrm{HMBH}$

\begin{tabular}{lcc}
\hline Sample & $R a(\mathrm{~nm})$ & $R q(\mathrm{~nm})$ \\
\hline Freshly polished metal & 34.2 & 45.0 \\
Metal + sulfuric acid & 102 & 133 \\
Metal $+\mathrm{H}_{2} \mathrm{SO}_{4}+\mathrm{HMBH}$ & 91.4 & 113 \\
\hline
\end{tabular}

Adsorption parameters for $\mathrm{HMBH}$ on CS surface in $0.5 \mathrm{M}$ $\mathrm{H}_{2} \mathrm{SO}_{4}$ are reported in Table 5 .

Figure $8 \mathrm{~b}$ shows the plot of $\Delta G^{o}$ ads vs. $T$ which gives a straight line. The standard enthalpy of adsorption $\left(\Delta H^{o}\right.$ ads $)$ and the standard entropy of adsorption $\left(\Delta S^{o}\right.$ ads $)$ values were calculated from the slope and intercept of the straight line obtained from the above plot using the equation [27].

$\Delta G_{\text {ads }}^{\circ}=\Delta H_{\text {ads }}^{\circ}-T \Delta S_{\text {ads }}^{\circ}$

The higher values of $K_{\text {ads }}$ suggest the formation of 

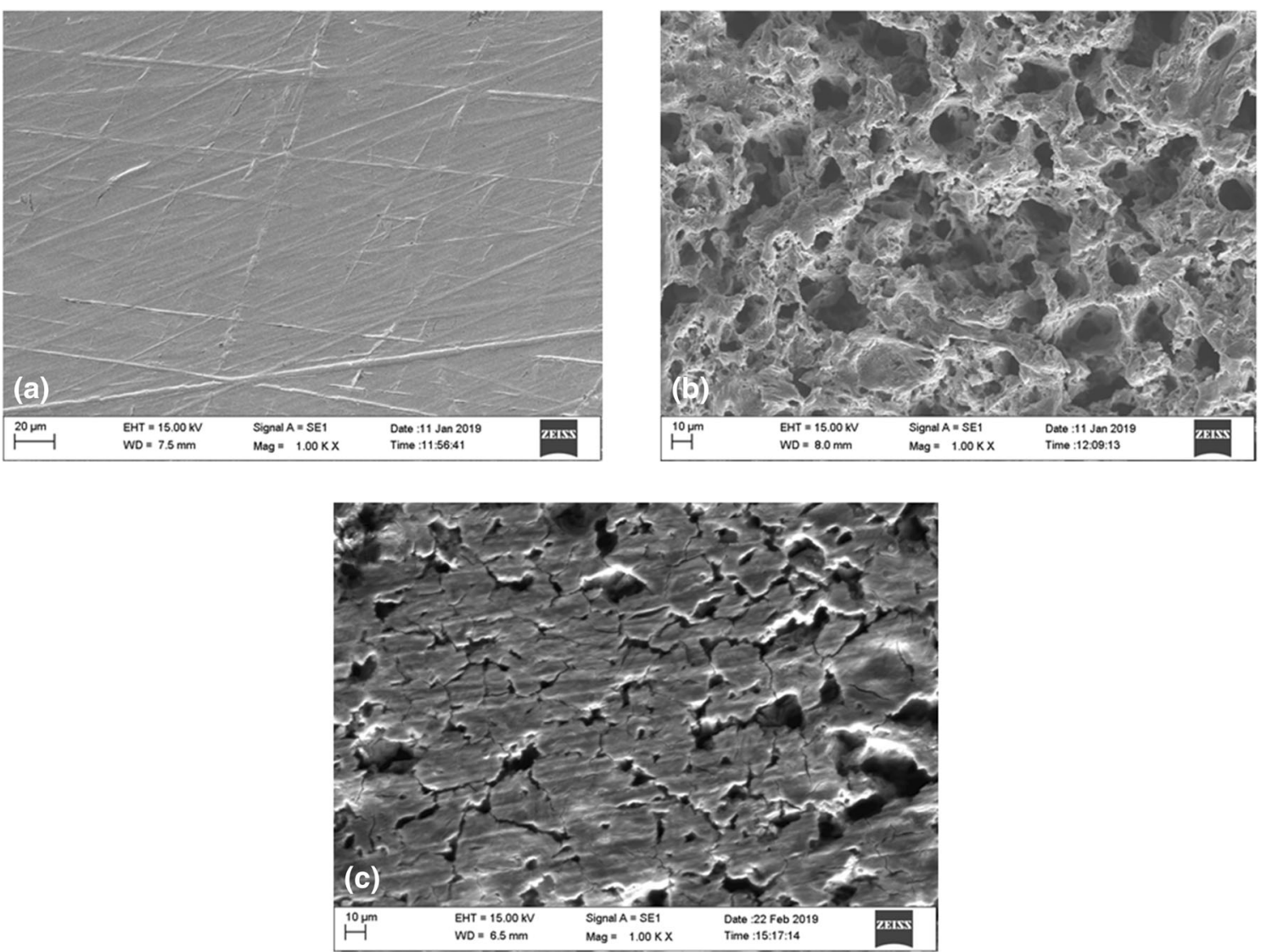

Fig. 11 Scanning electron microscopy images of CS surface (a) Freshly polished metal surface (b) immersed in $0.5 \mathrm{M} \mathrm{H}_{2} \mathrm{SO}_{4}$ and (c) immersed in $0.5 \mathrm{M} \mathrm{H}_{2} \mathrm{SO}_{4}$ containing $1 \mathrm{mM}$ of $\mathrm{HMBH}$.

stronger and more stable adsorbed layer on the metal surface, resulting in the higher inhibition efficiency. The reactive centers present in the inhibitor molecules get attached on both anodic and cathodic sites present on the metal replacing the water molecule which was initially adsorbed on the metal surface. The $\Delta G_{\text {ads }}^{o}$ values are found to be in the range of $-20 \mathrm{~kJ} \mathrm{~mol}^{-1}$. The mode of adsorption of inhibitor on CS physical adsorption is an indication. The negative values of $\Delta H^{o}$ ads indicate that adsorption is taking place through physical adsorption [28]. The negative values of $\Delta S^{o}$ ads in the acid medium indicate the decrease in the dis-orderness because of formation of more ordered adsorbed species [29].

\section{Corrosion Inhibition Mechanism}

The inhibition effect of HMBH on the corrosion of CS in $0.5 \mathrm{M} \mathrm{H}_{2} \mathrm{SO}_{4}$ solution may be attributed to the adsorption of the inhibitor at the metal/solution interface. The free electron pairs of oxygen and nitrogen atoms, $\pi$-electrons on the aromatic rings, imine group, electron-donating group and molecular size of HMBH help its adsorption and form coordinate bonds with the metal. The adsorbed HMBH may form a surface film, which acts as a physical barrier to restrict diffusion of metal ions to or from the metal surface and hence slows down the corrosion process. The type of adsorption between HMBH and metal surface is mixed. The adsorption of the inhibitor majorly depends on the nature of the metal, structure of inhibitors, temperature, type of aggressive medium and the morphology of the CS surface $[30,31]$. The corrosion inhibition mechanism can be described as follows. HMBH gets protonated in acid medium at the nitrogen atom of the hydrazide group, which results in formation of positively charged inhibitor species, which will electrostatically interact with the negative charge formed at metal/solution interface, thereby facilitating physisorption. Chemical adsorption of HMBH arises from the interactions between the free electron pairs of heteroatoms and $\pi$-electrons of multiple bonds in addition to vacant d-orbitals of iron [32]. Figure 9 depicts the mechanism of corrosion inhibition. 


\section{Surface Morphological Study}

\section{Atomic Force Microscopy (AFM)}

The 3-dimensional AFM images of polished CS surfaces, specimen immersed in $0.5 \mathrm{M} \mathrm{H}_{2} \mathrm{SO}_{4}$ in the absence and presence of $\mathrm{HMBH}$, are shown in Fig. 10a, b and c, respectively. The images obtained in the presence of HMBH exhibited a smoother surface. Average surface roughness $(R a)$ and roughness $(R q)$ values obtained for 0.5 $\mathrm{M} \mathrm{H}_{2} \mathrm{SO}_{4}$ in the absence and presence of inhibitor are given in Table 6 . The decrease in the $R a$ and $R q$ values clearly indicates the adsorption of inhibitor molecule on the metal surface [33].

\section{Scanning Electron Microscopy}

SEM images of the polished metal, metal surface after immersion in $0.5 \mathrm{M} \mathrm{H}_{2} \mathrm{SO}_{4}$ acid for 3 hours and metal surface immersed in $0.5 \mathrm{M} \mathrm{H}_{2} \mathrm{SO}_{4}$ acid containing $1 \mathrm{mM}$ HMBH for the same time are shown in Fig. $11 \mathrm{a}, \mathrm{b}$ and c, respectively.

Figure $11 \mathrm{~b}$ shows the surface is rough due to the presence of cracks and pits. In Fig. 11c the surface is relatively smooth, due to the adsorption of HMBH onto the surface of the metal.

\section{Conclusions}

Centered on the results of the study, the subsequent conclusions are drawn:

- (E)-N'-(3-hydroxy-4-methoxy-benzylidene)-4-hydroxybenzohydrazide can be a potential inhibitor for the corrosion control of CS in $0.5 \mathrm{M} \mathrm{H}_{2} \mathrm{SO}_{4}$.

- $\mathrm{HMBH}$ is a mixed type of inhibitor for corrosion of CS in $0.5 \mathrm{M} \mathrm{H}_{2} \mathrm{SO}_{4}$.

- Percentage inhibition efficiency increases with increase in inhibitor concentrations and with decrease in temperature.

- The adsorption of inhibitor on CS surface obeys the Freundlich's adsorption isotherm in $0.5 \mathrm{M} \mathrm{H}_{2} \mathrm{SO}_{4}$.

- Corrosion rates computed by EIS and PDP are in good agreement.

Acknowledgment The authors are grateful to the Manipal Institute of Technology, Manipal Academy of Higher Education, Manipal, for its laboratory facilities.

Funding Open access funding provided by Manipal Academy of Higher Education, Manipal.
Open Access This article is licensed under a Creative Commons Attribution 4.0 International License, which permits use, sharing, adaptation, distribution and reproduction in any medium or format, as long as you give appropriate credit to the original author(s) and the source, provide a link to the Creative Commons licence, and indicate if changes were made. The images or other third party material in this article are included in the article's Creative Commons licence, unless indicated otherwise in a credit line to the material. If material is not included in the article's Creative Commons licence and your intended use is not permitted by statutory regulation or exceeds the permitted use, you will need to obtain permission directly from the copyright holder. To view a copy of this licence, visit http://creativecommons. org/licenses/by/4.0/.

\section{References}

1. N. Gunavathy, S.C. Murugavel, Study on the effect of Musa Acuminata flower extract on the (corrosion inhibition of mild steel in $1 \mathrm{~N} \mathrm{H}_{2} \mathrm{SO}_{4}$. Int. J. Chem. 11(1), 475-486 (2013)

2. S.A. Umoren, U.M. Eduok, E.E. Oguzie, Corrosion inhibition of mild steel in $1 \mathrm{M} \mathrm{H}_{2} \mathrm{SO}_{4}$ by polyvinyl pyrrolidone and synergistic iodide additives. Port. Electrochimi. Acta. 26(6), 533-546 (2008)

3. G. Bereket, A. Yurt, The inhibition effect of amino acids and hydroxyl carboxylic acids on pitting corrosion of aluminium alloy 7075. Corros. Sci. 43(6), 1179-1195 (2001)

4. K.F. Khaled, M.M. Al-Qahtani, The inhibitive effect of some tetrazole derivatives towards $\mathrm{Al}$ corrosion in acid solution: Chemical, electrochemical and theoretical studies. Mater. Chem. Phys. 113(1), 150-158 (2009)

5. P. Kumari, P. Shetty, S.A. Rao, D. Sunil, Corrosion inhibition and adsorption behaviour of (2E)-2-(3-hydroxy benzylidene) hydrazine carbothiamide on mild steel in $1 \mathrm{M} \mathrm{HCl}$. Rev. Roum. Chim. 59(5), 323-333 (2014)

6. W. Li, Q. He, S.-T. Zhang, C.-H. Pei, B.-T. Hou, Some new triazole derivatives as inhibitors for mild steel corrosion in acidic medium. J. Appl. Electrochem. 38, 289-295 (2008)

7. P. Mohan, K.A. Kumar, G.P. Kalaignan, V.S. Muralidharan, N'(4-Methoxybenzylidene) benzohydrazide as effective corrosion inhibitor for mild steel in $1 \mathrm{M} \mathrm{HCl}$. Chem. Asian J. 24(12), 58215823 (2012)

8. A.S. Fouda, M.T. Mohamed, M.R. Soltan, Role of some benzohydrazide derivatives as corrosion inhibitors for carbon steel in $\mathrm{HCl}$ solution. J. Electrochem. Sci. 4(2), 61-70 (2013)

9. M. Yadav, R.R. Sinha, S. Kumar, I. Bahadur, E.E. Ebenso, Synthesis and application of new acetohydrazide derivatives as a corrosion inhibition of mild steel in acidic medium: Insight from electrochemical and theoretical studies. J. Mol. Liq. 208, 322$332(2015)$

10. L. Larabi, Y. Harek, O. Benali, S. Ghalem, Hydrazide derivatives as corrosion inhibitors for mild steel in $1 \mathrm{M} \mathrm{HCl}$. Prog. Org. Coat. 54(3), 256-262 (2005)

11. K.F. Khaled, O.A. Elhabib, A. El-Mghraby, O.B. Ibrahim, A.M. Magdy Ibrahim, Inhibitive effect of thiosemicarbazone derivative on corrosion of mild steel in hydrochloric acid solution. J. Mater. Environ. Sci. 1(3), 139-150 (2010)

12. A.A. El-Shafei, M.N.H. Moussa, A.A. El-Far, The corrosion inhibition character of thiosemicarbazide and its derivatives for C-steel in hydrochloric acid solution. Mater. Chem. Phys. 70(2), 175-180 (2001)

13. C.M. Goulart, A. Esteves-Souza, C.A. Martinez-Huitle, C.J.F. Rodrigues, M.A.M. Maciel, A. Echevarria, Experimental and theoretical evaluation of semicarbazones and thiosemicarbazones as organic corrosion inhibitors. Corros. Sci. 67, 281-291 (2013) 
14. Y. Meng, W. Ning, B. Xu, W. Yang, K. Zhang, Y. Chen, L. Li, X. Liu, J. Zheng, Y. Zhang, Inhibition of mild steel corrosion in hydrochloric acid using two novel pyridine Schiff base derivatives: a comparative study of experimental and theoretical results. RSC Adv. 7(68), 43014-43029 (2017)

15. R.V. Saliyan, A.V. Adhikari, Corrosion inhibition of mild steel in acid media by quinolinyl thiopropano hydrazone. Indian J. Chem. Technol. 16(2), 162-174 (2009)

16. M. Abdallah, Guar gum as corrosion inhibitor for carbon steel in sulfuric acid solutions. Port. Electrochimica Acta. 22(2), 161-175 (2004)

17. W. Li, Q. He, C. Pei, B. Hou, Experimental and theoretical investigation of the adsorption behaviour of new triazole derivatives as inhibitors for mild steel corrosion in acid media. Electrochim. Acta. 52(22), 6386-6394 (2007)

18. W. Li, Q. He, S. Zhang, C. Pei, B. Hou, Some new triazole derivatives as inhibitors for mild steel corrosion in acidic medium. J. Appl. Electrochem. 38(3), 289-295 (2007)

19. M.A. Amin, S.S. Abd El-Rehim, E.E.F. El-Sherbini, R.S. Bayoumi, The inhibition of low carbon steel corrosion in hydrochloric acid solutions by succinic acid. Electrochim. Acta. 52(11), 3588-3600 (2007)

20. U.M. Eduok, S.A. Umoren, A.P. Udoh, Synergistic inhibition effects between leaves and stem extracts of Sida acuta and iodide ion for mild steel corrosion in $1 \mathrm{M} \mathrm{H}_{2} \mathrm{SO}_{4}$ solutions. Arab. J. Chem. 5(3), 325-337 (2012)

21. K.S. Shaju, K. Joby Thomas, V.P. Raphael, A. Paul, Electrochemical and surface morphological studies of carbon steel corrosion by a novel polynuclear Schiff base in $\mathrm{HCl}$ solution. ISRN Electrochem. 55, 1-8 (2013)

22. P. Kumar, A.N. Shetty, Electrochemical investigation on the corrosion of $18 \% \mathrm{Ni}$ M250 grade maraging steel under welded condition in sulfuric acid medium. Surf. Eng. Appl. Electrochem. 49, 253-260 (2013)

23. P. Lowmunkhong, D. Ungthararak, P. Sutthivaiyakit, Tryptamine as a corrosion inhibitor of mild steel in hydrochloric acid solution. Corros. Sci. 52(1), 30-36 (2010)

24. P. Kumari, P. Shetty, S.A. Rao, D. Sunil, Inhibition Behaviour of 2-[(2-Methylquinolin-8-yl) Oxy] Acetohydrazide on the Corrosion of Mild Steel in Hydrochloric Acid Solution. T Indian I Metals. 70(4), 1139-1150 (2016)
25. F. Bentiss, M. Lebrini, M. Lagrenée, Thermodynamic characterization of metal dissolution and inhibitor adsorption processes in mild steel/2, 5-bis (n-thienyl)-1, 3, 4-thiadiazoles/hydrochloric acid system. Corros. Sci. 47(12), 2915-2931 (2005)

26. R.T. Loto, C.A. Loto, A.L. Olaitan, P.O. Babalola, Evaluation of the synergistic properties of 4-hydroxy-3-methoxybenzaldehyde and 1, 4-diaminobenzene on the electrochemical corrosion behaviour of mild steel in dilute acid solutions. Mor. J. Chem. 5(1), 81-95 (2017)

27. I. Ahamad, R. Prasad, M.A. Quraishi, Thermodynamic, electrochemical and quantum chemical investigation of some Schiff bases as corrosion inhibitors for mild steel in hydrochloric acid solutions. Corros. Sci. 52(3), 933-942 (2010)

28. A.S. Raja, V. Prathipa, Experimental study of inhibition effect, synergistic effect and antagonistic behaviour of L-phenylalanine $-\mathrm{ZnSO}_{4}$ at $\mathrm{pH}-7.2$ and isoelectric point $(\mathrm{pH}-5.9)$ on carbon steel in aqueous solution. Int. J. Chem. Tech. Res. 8, 134-142 (2015)

29. S.S. Shivakumar, K.N. Mohana, Studies on the inhibitive performance of Cinnamomum zeylanicum extracts on the corrosion of mild steel in hydrochloric acid and sulphuric acid media. J. Mater. Environ. Sci. 4(3), 448-459 (2013)

30. M.A. Amin, M.M. Ibrahim, Corrosion and corrosion control of mild steel in concentrated $\mathrm{H}_{2} \mathrm{SO}_{4}$ solutions by a newly synthesized glycine derivative. Corros. Sci. 53(3), 873-885 (2011)

31. E.E. Ebenso, N.O. Eddy, A.O. Odiongenyi, Corrosion inhibitive properties and adsorption behaviour of ethanol extract of Piper guinensis as a green corrosion inhibitor for mild steel in $\mathrm{H}_{2} \mathrm{SO}_{4}$. Afr. J. Pure Appl. Chem. 2(11), 07-115 (2008)

32. S.A. Umoren, I.B. Obot, N.O. Obi-Egbedi, Raphia hookeri gum as a potential eco-friendly inhibitor for mild steel in sulfuric acid. J. Mater. Sci. 44(1), 274-279 (2009)

33. R.B. de Oliveira, E.M. de Souza-Fagundes, R.P.P. Soares, A.A. Andrade, A.U. Krettli, C.L. Zani, Synthesis and antimalarial activity of semicarbazone and thiosemicarbazone derivatives. Eur. J. Med. Chem. 43(9), 1983-1988 (2008)

Publisher's Note Springer Nature remains neutral with regard to jurisdictional claims in published maps and institutional affiliations. 